\title{
Neuropathology of the posteroinferior occipitotemporal gyrus in children with autism
}

\author{
Neha Uppal ${ }^{1,2,3,4}$, Isabella Gianatiempo 1,2,6, Bridget Wicinski ${ }^{1,2}$, James Schmeidler ${ }^{5}$, Helmut Heinsen", \\ Christoph Schmitz ${ }^{8}$, Joseph D Buxbaum ${ }^{2,3,4,5}$ and Patrick R Hof ${ }^{1,2,4^{*}}$
}

\begin{abstract}
Background: While most neuropathologic studies focus on regions involved in behavioral abnormalities in autism, it is also important to identify whether areas that appear functionally normal are devoid of pathologic alterations. In this study we analyzed the posteroinferior occipitotemporal gyrus, an extrastriate area not considered to be affected in autism. This area borders the fusiform gyrus, which is known to exhibit functional and cellular abnormalities in autism.

Findings: No studies have implicated posteroinferior occipitotemporal gyrus dysfunction in autism, leading us to hypothesize that neuropathology would not occur in this area. We indeed observed no significant differences in pyramidal neuron number or size in layers III, V, and VI in seven pairs of autism and controls.

Conclusions: These findings are consistent with the hypothesis that neuropathology is unique to areas involved in stereotypies and social and emotional behaviors, and support the specificity of the localization of pathology in the fusiform gyrus.
\end{abstract}

Keywords: Autism, Fusiform gyrus, Neuropathology, Posteroinferior occipitotemporal gyrus, Stereology

\section{Findings}

\section{Introduction}

Neuropathology in autism is typically characterized by subtle alterations in brain regions known to contribute to the behavioral phenotype of the disorder. However, it is important to consider the degree to which these changes are not widespread, but rather are region- and cell-selective, directly influencing the behavior associated with a particular area (for review, see [1]). To assess this further, we analyzed the posteroinferior occipitotemporal gyrus (PIOTG), an extrastriate area directly adjacent to the fusiform gyrus (FG). The FG, which contains the fusiform face area (FFA), is involved in facial processing and therefore is crucial for social communication [2]. As impaired social communication is characteristic of autism [3], a significant effort has been directed towards determining the underlying areas or circuits that may

\footnotetext{
* Correspondence: patrick.hof@mssm.edu

${ }^{1}$ Fishberg Department of Neuroscience, Icahn School of Medicine at Mount

Sinai, One Gustave L Levy Place, Box 1639, New York, NY 10029, USA

${ }^{2}$ Friedman Brain Institute, Icahn School of Medicine at Mount Sinai, New

York, NY, USA

Full list of author information is available at the end of the article
}

cause this impairment, which often includes the FFA. Many studies report FFA hypoactivation in patients with autism when observing faces (for example, see [4]) and reduced connectivity [5], which may partly explain the social impairments representative of autism. These abnormalities in functional imaging led van Kooten et al. [6] to determine whether neuropathologic changes substantiate these functional deficits. In line with their hypothesis, the authors found reduced neuronal number, density, and size in layers III, V, and VI in the FG in patients with autism. No differences were observed in the primary visual cortex, suggesting that while the FG may not properly communicate with areas involved in 'social' processing, primary visual information processing is not affected in autism.

Because neuropathologic changes are reported in areas that are both behaviorally and functionally affected, of which the PIOTG is seemingly neither, we did not expect differences in number or size of pyramidal neurons in patients with autism. This result would support the specificity of the neuropathologic data reported by van Kooten et al. [6]. 


\begin{tabular}{|c|c|c|c|c|c|c|c|c|c|c|}
\hline Case & Diagnosis & $\begin{array}{c}\text { Age } \\
\text { (years) }\end{array}$ & Sex & Hemisphere & $\begin{array}{l}\text { Cut } / \text { mounted } \\
\text { thickness }(\mu \mathrm{m})\end{array}$ & PMI (hours) & BW (grams) & Cause of death & Relevant clinical information & ADI-R \\
\hline \multirow[t]{4}{*}{$425-02$} & \multirow[t]{4}{*}{$\mathrm{A} 1$} & \multirow[t]{4}{*}{4} & \multirow[t]{4}{*}{ M } & \multirow[t]{4}{*}{$L$} & \multirow[t]{4}{*}{ 200/178.5 } & \multirow[t]{4}{*}{30} & \multirow[t]{4}{*}{1,160} & \multirow[t]{4}{*}{ Drowning } & Symptoms present at two years & \multirow[t]{4}{*}{$14,10(\mathrm{NV}), 3$} \\
\hline & & & & & & & & & Frequent tantrums and self-injurious behavior & \\
\hline & & & & & & & & & $\begin{array}{l}\text { Used parents' hand to reach objects, echolalia, } \\
\text { tendency to walk on his tiptoes }\end{array}$ & \\
\hline & & & & & & & & & Stereotypic play & \\
\hline $15-763-95$ & C1 & 4 & M & L & $600 / 574.1$ & 3 & 1,380 & Myocardial infarct & No known disorder & - \\
\hline \multirow[t]{3}{*}{$425-02$} & \multirow[t]{3}{*}{$\mathrm{A} 2$} & \multirow[t]{3}{*}{4} & \multirow[t]{3}{*}{ M } & \multirow[t]{3}{*}{$\mathrm{R}$} & \multirow[t]{3}{*}{ 200/165.6 } & \multirow[t]{3}{*}{30} & \multirow[t]{3}{*}{1,160} & \multirow[t]{3}{*}{ Drowning } & Symptoms present at two years & \multirow[t]{3}{*}{$14,10(N V), 3$} \\
\hline & & & & & & & & & Frequent tantrums and self-injurious behavior & \\
\hline & & & & & & & & & $\begin{array}{l}\text { Used parents' hand to reach objects, echolalia, } \\
\text { tendency to walk on his tiptoes }\end{array}$ & \\
\hline
\end{tabular}

$\begin{array}{ccccccccc}15-763-95 & \text { C2 } & 4 & M & R & 600 / 575.6 & 3 & 1,380 & \text { Myocardial infarct } \\ \text { M6-06 } & \text { A3 } & 7 & \text { M } & \text { R } & 200 / 176.6 & 25 & 1,610 & \text { Drowning }\end{array}$

Stereotypic play

No known disorder

Regression after first seizure at 14 months

No spontaneous meaningful language

Used parents' hands as a tool

No reciprocal social smiling or eye contact

Stereotypic play

Psychiatric and developmental disorders

on maternal side

\begin{tabular}{|c|c|c|c|c|c|c|c|c|c|c|}
\hline M15-06 & C3 & 7 & M & $\mathrm{R}$ & $200 / 190.2$ & 12 & 1,240 & Drowning & No known disorder & - \\
\hline \multirow[t]{4}{*}{ M5-03 } & A4 & 8 & M & $\mathrm{R}$ & $200 / 182.1$ & 22.2 & 1,570 & Rhabdomyo-sarcoma & Symptoms present at three years & $19,14(V), 4$ \\
\hline & & & & & & & & & $\begin{array}{l}\text { Engaged in repetitive play, jumping up and down } \\
\text { on his tiptoes, echolalia }\end{array}$ & \\
\hline & & & & & & & & & Cancer diagnosis at age six & \\
\hline & & & & & & & & & Abnormal EEG & \\
\hline M3-04 & C4 & 8 & $\mathrm{~F}$ & $\mathrm{R}$ & $200 / 182.8$ & 20 & 1,222 & Multiple injuries & No known disorder & - \\
\hline \multirow[t]{4}{*}{ 427-02 } & A5 & 11 & $\mathrm{~F}$ & L & $200 / 177.9$ & 13 & 1,460 & Drowning & Tonic-clonic seizures & $22,14(V), 3$ \\
\hline & & & & & & & & & Developmental, intellectual, and language delays & \\
\hline & & & & & & & & & Poor eye contact & \\
\hline & & & & & & & & & Poor social interaction & \\
\hline M9-03 & C5 & 14 & M & $\mathrm{R}$ & $200 / 188.8$ & 20 & 1,464 & Electrocution & No known disorder & - \\
\hline M5-05 & A6 & 17 & $\mathrm{~F}$ & L & 200/153.6 & 25 & 1,580 & Cardiac arrest & Difficulty with reciprocal social interaction & 29, 14 (NV), 3 \\
\hline
\end{tabular}


Table 1 Demographic and clinical data of patients with autism and controls (Continued)

Appropriate emotional response to her family,

but not to others

Non-social use of language

Stereotypic behaviors

$\begin{array}{lllllllll}\text { M16-06 } & \text { C6 } & 15 & F & R & \text { 200/174.6 } & 9 & 1,250 & \text { Multiple injuries }\end{array}$

$\begin{array}{llllllll}\text { M1-03 A7 } & 21 & F & R & \text { 200/263.6 } & 50 & 1,108 & \text { Obstructive pulmonary disease Seizures }\end{array}$

$21,11(\mathrm{NV}), 3$

Engaged in repetitive play, bouncing up and

down on her tiptoes, echolalia

Abnormal EEG

$\begin{array}{lllllllll}\text { M1-07 } & \text { C7 } & 20 & F & R & 200 / 187.1 & 9 & 1,340 & \text { Multiple injuries }\end{array}$

ADI-R scores listed as Qualitative Abnormalities in Reciprocal Social Interaction, Qualitative Abnormalities in Communication (V=verbal, NV=nonverbal), and Restricted, Repetitive and Stereotyped Patterns of Behavior, respectively. Cut-off scores for autism are $10, \mathrm{~V}=8$ or $\mathrm{NV}=7$, and 3 , in order listed above. BW, brain weight; PMI, postmortem interval. 


\section{Materials and methods Subjects}

A total of 12 postmortem brains were analyzed (one hemisphere per case, excluding one autism case and one control for which both hemispheres were available; see Table 1 for details). Accounting for all hemispheres, seven pairs were analyzed. Age range of the cases spanned several developmental stages in order to identify potential developmental changes in the parameters assessed. Tissue processing was performed as previously described [7-9]. This work involved exclusively postmortem materials and was approved by Autism Speaks and the Icahn School of Medicine at Mount Sinai Institutional Review Board. All postmortem materials used in this study were directly obtained from Autism Speaks. All necessary consent was obtained in writing by the patients or their next of kin and confirmed at time of death. Demographic and clinical data are shown in Table 1.

\section{Regional definition}

Although the visual cortex is rather coarsely parsed into Brodmann areas, the PIOTG has recently been characterized by Caspers et al. [10]. The PIOTG (Figure 1A-D) is contained within their area 'FG2', lateral to 'FG1'. FG1 is located on the medial posterior FG, while FG2 is located on the lateral FG, which reaches into the lateral occipitotemporal sulcus [10]. FG2 extends further anteriorly and posteriorly than the expanse of the PIOTG; we
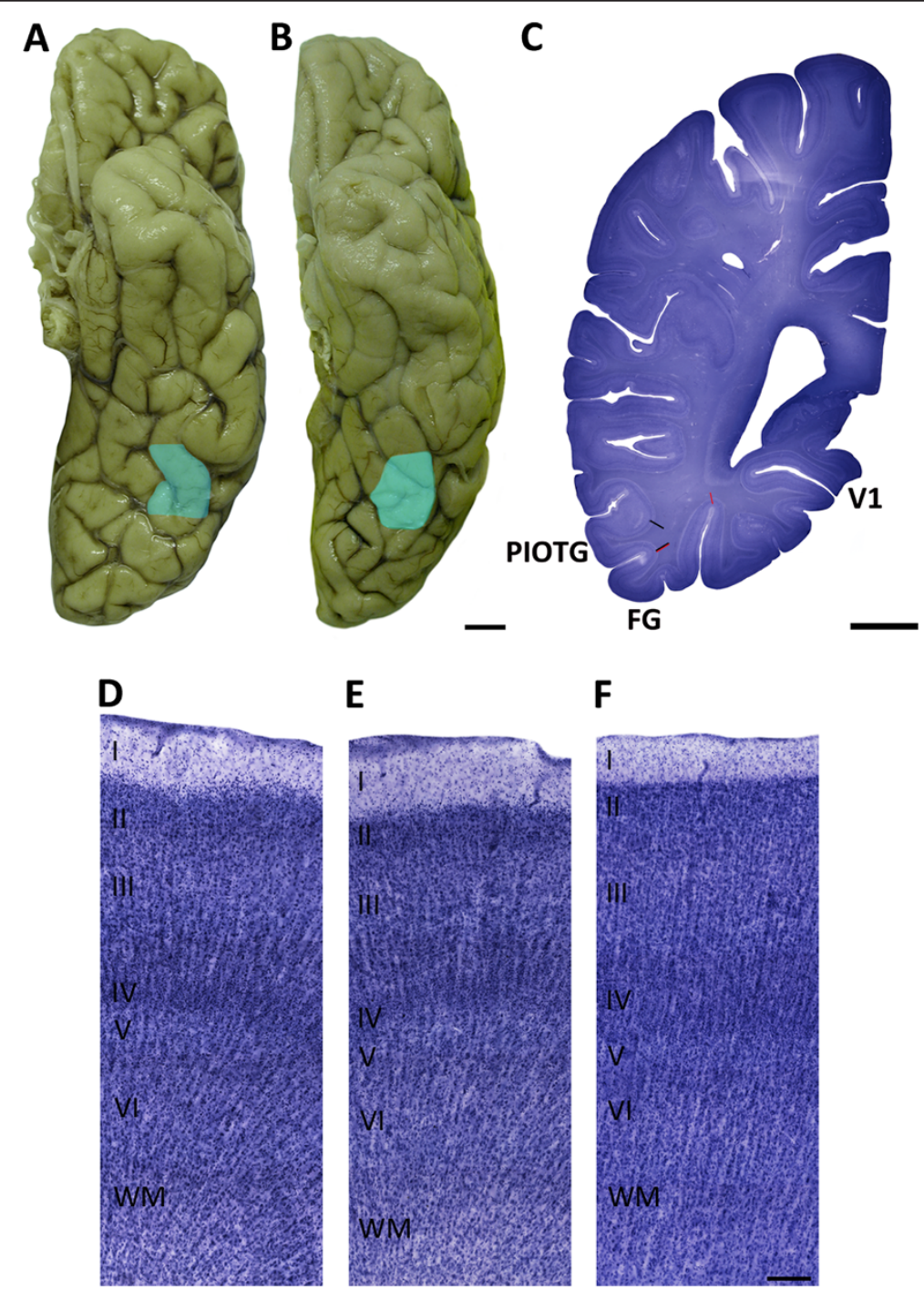

E

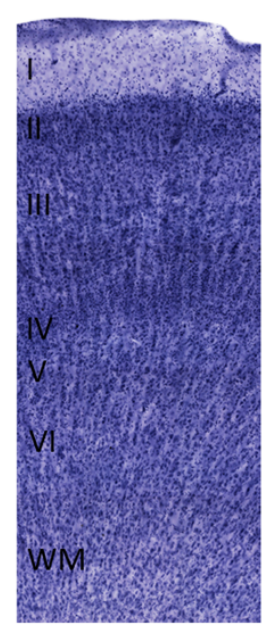

$\mathbf{F}$

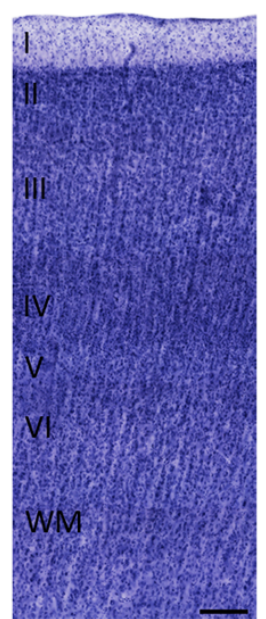

Figure 1 Cytoarchitectural characteristics of the posteroinferior occipitotemporal gyrus (PIOTG). (A,B) Left hemisphere of ventral human brain indicating the PIOTG in blue, (C) right hemisphere of a coronal human brain section stained with gallocyanin, indicating the PIOTG and FG2 within the two black lines and FG1 within the two red lines, (D-F) photomicrographs showing the cytoarchitectural characteristics of (D) the PIOTG, (E) anterior neighboring area 37 and (F) posterior area 19. Scale bar $=2 \mathrm{~cm}$ (A, B), $1 \mathrm{~cm}$ (C), and $200 \mu \mathrm{m}$ (D-F). FG, fusiform gyrus; PIOTG, posteroinferior occipitotemporal gyrus; V1, primary visual cortex; cc, corpus callosum; WM, white matter. 
Table 2 Stereologic parameters used for pyramidal neuron quantification in control subjects and patients with autism

\begin{tabular}{lc}
\hline Number of sections (average) & 7.7 \\
Objective 1 & $2.5 \times$ \\
Objective 2 & $40 \times$ \\
Disector height & $20 \mu \mathrm{m}$ \\
Guard zone & $5 \mu \mathrm{m}$ \\
Counting frame & $75 \times 75 \mu \mathrm{m}$ \\
Grid size & Layer III: $750 \times 750 \mu \mathrm{m}$ \\
& Layer V: $500 \times 500 \mu \mathrm{m}$ \\
& Layer VI: $500 \times 500 \mu \mathrm{m}$ \\
Measured thickness $(\mu \mathrm{m}$, average) & Cut at $200 \mu \mathrm{m}: 185.1$ \\
& Cut at $600 \mu \mathrm{m}: 574.8$
\end{tabular}

Nucleator rays

4

Cavalieri grid size

$100 \times 100 \mu \mathrm{m}$

restricted our region of interest to accurately and consistently sample the same area in each case.

The PIOTG is a granular cortex, with a dense layer IV and well defined laminar architecture (Figure 1D). Layer II is highly populated, whereas its neighboring layer IIIa is noticeably less dense. Layers IIIb and IIIc have characteristic large pyramidal neurons, and the density of neurons increases near IIIc. The border between layer IIIc and layer IV is somewhat indistinct, though layer IV is distinguishable by its very dense and granular appearance. The medium-sized pyramidal neurons in layer $\mathrm{V}$ are evenly concentrated throughout the layer, contrasting with the denser layer VI.

The PIOTG was defined anteriorly by the caudal-most level of the subiculum, and posteriorly by marked columnar neuronal organization. Thus, the PIOTG spans part of Brodmann area 37 (Figure 1E) and extends partially into area 19 (Figure 1 F; [11]). The cytoarchitecture of this junctional region was clearly described by von Economo [12], and we adopted his definition for this analysis. The temporo-occipital junction has a clear lamination pattern in layer III and a thin radial striation at times perceptible into layer IV. Layer V contains small pyramidal cells, with an indistinct border with layer VI. Extending posteriorly into area 19 is a progressively denser layer II, an increased cellularity of layer III, and isolated large neurons close to a distinct and dense layer IV. Layer V is rather thin with small pyramidal neurons

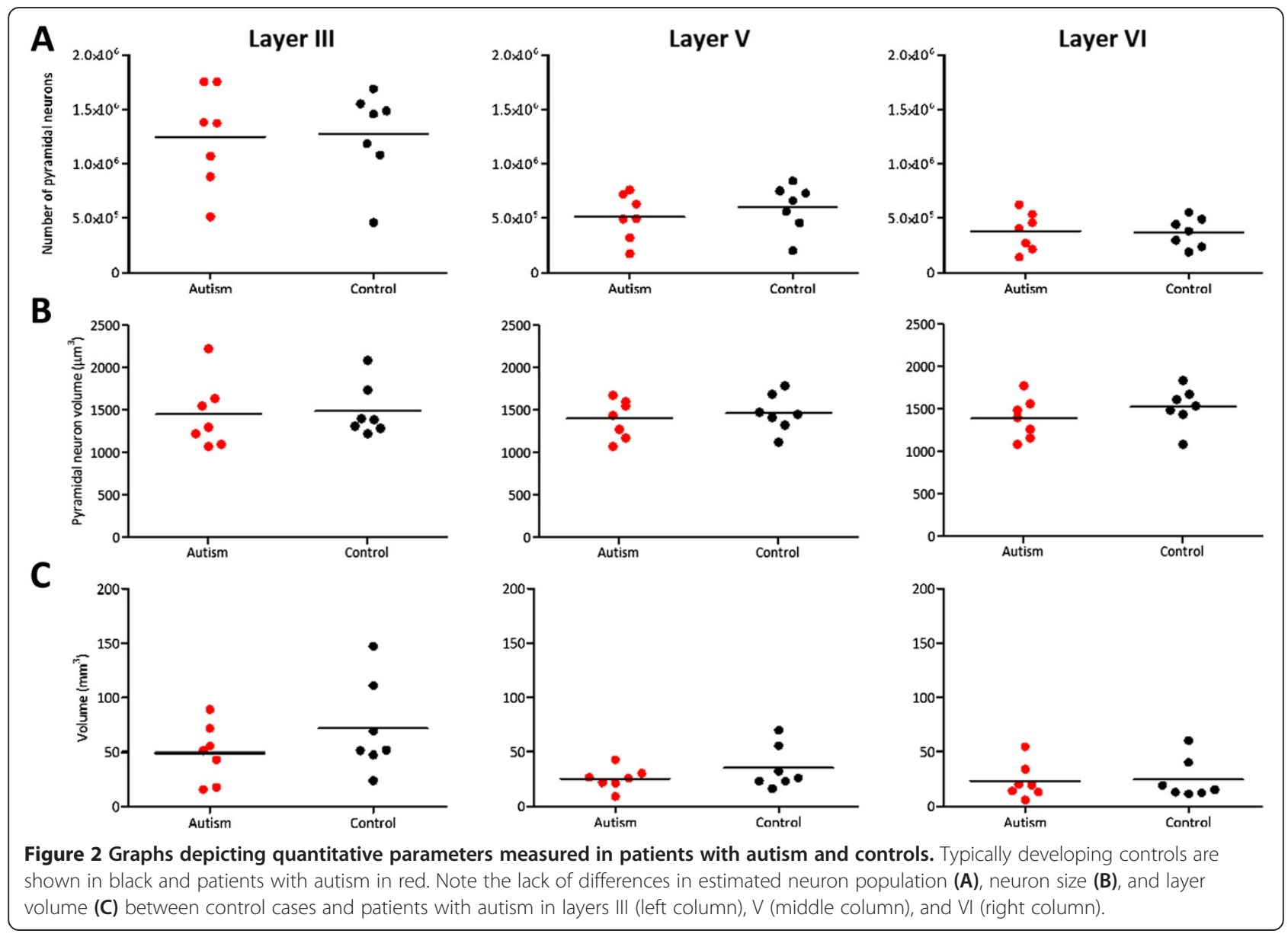


and isolated large neurons in its upper border, with a denser layer VI. We relied on the detailed description of Caspers et al. [10] for the dorso-ventral boundaries of our region of interest, within the more global context of the classical descriptions by Brodmann and von Economo $[11,12]$.

\section{Stereologic design}

For stereologic quantification, we selected every available section within the range of sections containing the PIOTG for each case (1:3 series for $200-\mu \mathrm{m}$ sections, 1:2 for 500 - and $600-\mu \mathrm{m}$ sections). The mounted thickness of these materials was calculated by averaging the measurements of a random sampling of ten sites per slide (40× objective) in the PIOTG.

Sampling grid dimensions were set to sample pyramidal neurons such that the coefficient of error was $\leq 0.1$ [13]. StereoInvestigator (MBF Bioscience, Willinston, VT, USA) defined a systematic-random sampling sequence of counting frames and grids within the outlines of each layer analyzed in the PIOTG, in which pyramidal neurons were quantified. Layers were defined at $2.5 \times$ and quantification occurred at 40×. Neurons were counted according to stereologic principles, estimating cell population with the Optical Fractionator [14], pyramidal neuron volume with the Nucleator [15], and total layer volume with the Cavalieri principle ([13,16]; Table 2$)$.

\section{Statistical analysis}

We compared seven hemispheres of patients with autism to seven hemispheres of controls. For statistical analysis, we used a matched-subject design, comparing each patient with an age-matched control using a paired $t$-test. Because pairs 1 and 2 compared two hemispheres from the same patient and control, we also conducted paired $t$-tests excluding either pair 1 or 2 to determine whether having both hemispheres confounded the results. Additionally, we used repeated measures analysis of variance to control for potential effects of age, gender, and postmortem interval. A $P$-value of 0.05 was used as the criterion for statistical significance. Calculations were performed with GraphPad Prism (version 5.03, GraphPad Software, San Diego, CA, USA) and SPSS (version 20, SPSS Inc., Chicago, IL, USA).

\section{Results}

Upon visual inspection, patients with autism and controls showed a similar cytoarchitecture, characteristic of the PIOTG (Figure 1D). We assessed pyramidal neuron number, pyramidal neuron volume, and layer size in layers III, $\mathrm{V}$, and VI in patients with autism and control subjects.

The paired samples $t$-test resulted in no significant differences in pyramidal neuron number in layers III $\left(t_{(6)}=0.091, P=0.9306\right), \mathrm{V}\left(t_{(6)}=0.709, P=0.5047\right)$, and
VI $\left(t_{(6)}=0.091, P=0.9305\right.$; Figure $\left.2 \mathrm{~A}\right)$. There was also no statistically significant difference in pyramidal neuron volume in layers III $\left(t_{(6)}=0.038, P=0.7169\right), \mathrm{V}\left(t_{(6)}=1.023\right.$, $P=0.3457)$, and VI $\left(t_{(6)}=1.32, P=0.2349\right.$; Figure $2 \mathrm{~B}$, Figure 3$)$. Volume of layers III $\left(t_{(6)}=1.236, P=0.2625\right), \mathrm{V}$ $\left(t_{(6)}=1.1, P=0.3136\right)$, and VI $\left(t_{(6)}=0.141, P=0.8928\right)$ were also not statistically different in patients with autism and controls (Figure 2C). Additionally, pyramidal neuron density was not statistically different in layers III $\left(t_{(6)}=1.4\right.$, $P=0.211), \mathrm{V}\left(t_{(6)}=0.271, P=0.7952\right)$, and VI $\left(t_{(6)}=0.278\right.$, $P=0.7905$; Table 3$)$. These results were still non-significant when either pair 1 or 2 was excluded from analysis (Table 4). In addition, when each covariate (age, gender, and postmortem interval) was added using repeated measured analysis of variance, we did not find any statistically significant differences between patients with autism and controls in any of the parameters assessed.

\section{Discussion}

The purpose of this study was to identify whether an area with little-known relevance to autism, the PIOTG, exhibited neuropathologic features present in areas associated with the behavioral abnormalities of autism. The significance of the PIOTG in particular is its proximity to the FG, an area well documented to be functionally and anatomically altered in autism. In line with our

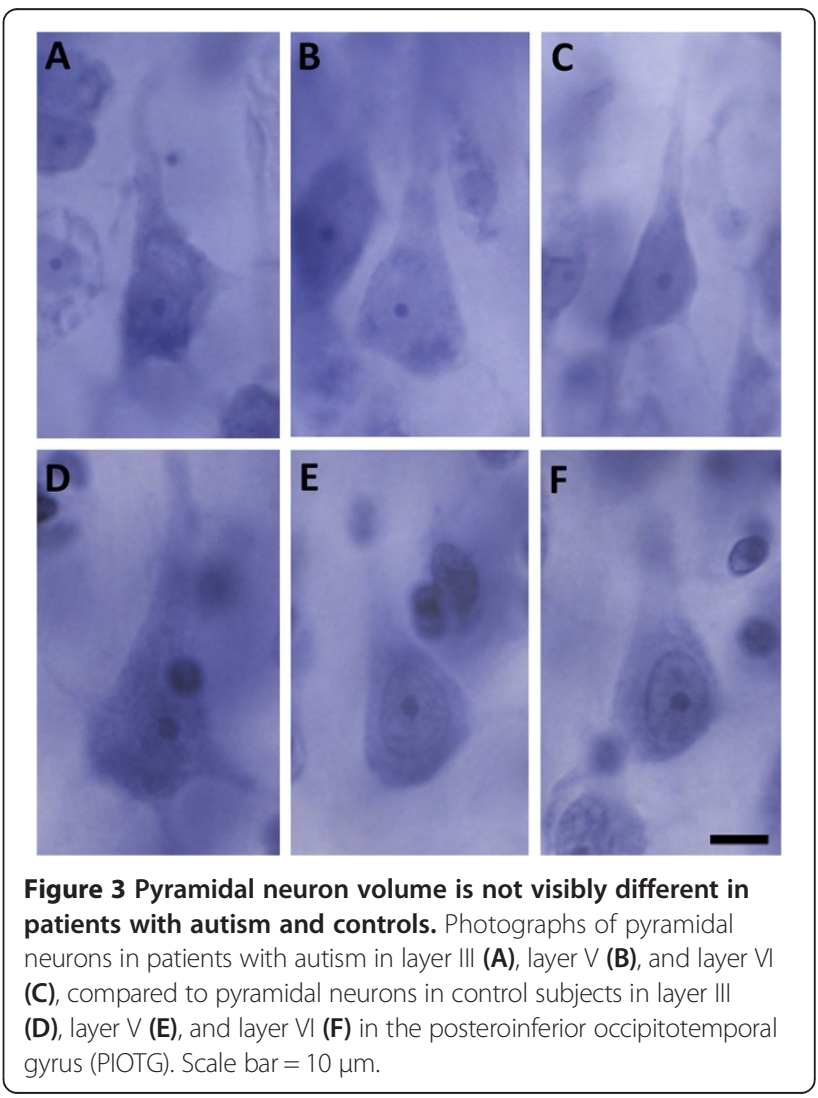


Table 3 Summary of stereologic results in control subjects and patients with autism

\begin{tabular}{lcc}
\hline Variable & Controls $($ mean \pm SD) & Autism (mean \pm SD) \\
\hline Pyramidal neuron number & \\
Layer III & $1.274 \times 10^{6} \pm 415515$ & $1.247 \times 10^{6} \pm 456858$ \\
Layer V & $600641 \pm 217605$ & $512054 \pm 213975$ \\
Layer VI & $369762 \pm 135770$ & $378581 \pm 176463$ \\
Pyramidal neuron volume $\left(\mu m^{3}\right)$ & \\
Layer III & $1491 \pm 309.1$ & $1446 \pm 403.2$ \\
Layer V & $1468 \pm 220.0$ & $1400 \pm 225.7$ \\
Layer VI & $1527 \pm 234.2$ & $1395 \pm 239.2$ \\
Layer volume $\left(\mathrm{mm}^{3}\right)$ & \\
Layer III & $49.26 \pm 26.66$ & $71.77 \pm 42.69$ \\
Layer V & $25.52 \pm 10.28$ & $35.27 \pm 19.79$ \\
Layer VI & $23.23 \pm 16.4$ & $24.71 \pm 18.6$ \\
Pyramidal neuron density $\left(1 / \mathrm{mm}^{3}\right)$ & \\
Layer III & $32687 \pm 24425$ & $20882 \pm 8094$ \\
Layer V & $20738 \pm 6849$ & $19826 \pm 9099$ \\
Layer VI & $19673 \pm 8341$ & $18304 \pm 6800$ \\
\hline
\end{tabular}

hypothesis, we found no significant differences in pyramidal neuron number, pyramidal neuron size, pyramidal neuron density, or layer volume in patients with autism compared to age-matched controls (Figures 2, 3). It is important to take the small sample size into consideration, as this is a limitation and does not allow for a formal power analysis; a larger cohort of cases would be more

Table 4 Summary of statistical results in control subjects and patients with autism

\begin{tabular}{lccc}
\hline Variable & $\begin{array}{c}\text { P-value for } \\
\text { all pairs }\end{array}$ & $\begin{array}{c}\boldsymbol{P} \text {-values without } \\
\text { pair 1 }\end{array}$ & $\begin{array}{c}\boldsymbol{P} \text {-values without } \\
\text { pair 2 }\end{array}$ \\
\hline \multicolumn{2}{l}{ Pyramidal neuron number } \\
Layer III & 0.9306 & 0.9736 & 0.858 \\
Layer V & 0.5047 & 0.6099 & 0.599 \\
Layer VI & 0.9305 & 0.6718 & 0.8253 \\
Pyramidal neuron volume & & \\
Layer III & 0.7169 & 0.7121 & 0.5754 \\
Layer V & 0.3457 & 0.328 & 0.2466 \\
Layer VI & 0.2349 & 0.3165 & 0.1626 \\
Layer volume & & & 0.4574 \\
Layer III & 0.2625 & 0.5003 & 0.5659 \\
Layer V & 0.3136 & 0.6044 & 0.8258 \\
Layer VI & 0.8928 & 0.6253 & 0.3386 \\
Pyramidal neuron density & & 0.4404 \\
Layer III & 0.2110 & 0.2596 & 0.7668 \\
Layer V & 0.7952 & 0.9194 & \\
Layer VI & 0.7905 & 0.9106 &
\end{tabular}

sensitive to potential neuropathology. In addition, it is of note that as demonstrated by the PIOTG, a longer postmortem interval and drowning as a cause of death are two factors that do not result in cytoarchitectural abnormalities in the measured parameters.

Although it is difficult to draw conclusions on functional correlates to an area that has only been characterized morphologically, Caspers et al. [10] suggested that FG2 is within a cortical region involved in higher-order object-related processing. More specifically, FG2 may correlate to a 'patch' of the FFA. Although this potential participation in face processing suggests an involvement in autism behaviorally, the role of the PIOTG is likely more general, based on its anatomical location (face processing becomes progressively more complex in more anterior areas). In fact, Caspers et al. confirmed the role of FG2 in face processing, and also uncovered functional lateralization in FG2: the left FG2 is active during visual language processing, while the right FG2 is more active during face processing [17]. FG2 participates in several functions related to visual and face processing, but the principal activation patterns suggest that it is situated early in the functional hierarchy of face processing, and is likely involved in pattern analysis [17]. The neuropathology in face processing areas occurs in areas predominantly involved in emotional or affective characteristics of faces, which FG2 (and therefore the PIOTG) are not. That being said, the PIOTG is still part of the face processing pathway, albeit early on, and there is a possibility that it is affected indirectly. Although all analyzed parameters did not reveal significant differences, patients with autism showed a slight trend towards a reduction for some of the assessed variables, as seen visually in Figure 2. This may indicate a peripheral effect from areas that interact with the PIOTG (for example, the FG, in which patients with autism have neuropathology [6]).

Overall, the PIOTG shows involvement in attentiondemanding visual processing, primarily in visual object recognition $[10,14]$. This higher-order visual area shows hemispheric lateralization that suggests functions in language, word, and face processing. Although we were unable to parse out potential hemispheric differences, we confirmed a lack of neuropathology in the PIOTG. This result is consistent with the concept that areas uninvolved in social, emotional, and stereotypic behaviors would not show cellular pathology in autism. This study provides a foundation for continuing efforts to characterize the brain in autism, as area-specific neuropathology can provide insight into potential altered cortical functioning.

\section{Availability of supporting data}

The data sets supporting the results of this article are included within the article; raw data are shared on the Autism Speaks portal. 


\section{Abbreviations}

FFA: fusiform face area; FG: fusiform gyrus; PIOTG: posteroinferior occipitotemporal gyrus.

\section{Competing interests}

The authors declare that they have no competing interests.

\section{Authors' contributions}

NU: conception and design, data collection, analysis, and interpretation, manuscript preparation, and final approval of the manuscript. IG: data collection, manuscript preparation, and final approval of the manuscript. BW: data collection, manuscript preparation, and final approval of the manuscript. JS: data analysis and interpretation, critical revision and final approval of the manuscript. $\mathrm{HH}$ : processed all materials, critical revision and final approval of the manuscript. CS: conception and design, processed all materials, data interpretation, critical revision, and final approval of the manuscript. JDB: conception and design, data interpretation, critical revision and final approval of the manuscript. PRH: conception and design, data interpretation, manuscript preparation, and final approval of the manuscript. All authors read and approved the final manuscript.

\section{Acknowledgements}

This study was supported by the Seaver Foundation (NU, JDB), Autism Speaks (CS, PRH), the James S McDonnell Foundation (PRH), and the Simons Foundation (PRH, JDB). We thank Dr. Jane Pickett and Dr. Jerzy Wegiel for securing the precious materials used in this study. Most of all, we are deeply indebted to the patients' families, who have made this study possible. Written informed consent was obtained from the patients and their relatives for publication of this manuscript and accompanying images. In compliance with Autism Speaks policies, all data generated by this study will be available on the Autism Speaks portal.

\section{Author details}

${ }^{1}$ Fishberg Department of Neuroscience, Icahn School of Medicine at Mount Sinai, One Gustave L Levy Place, Box 1639, New York, NY 10029, USA.

${ }^{2}$ Friedman Brain Institute, Icahn School of Medicine at Mount Sinai, New York, NY, USA. ${ }^{3}$ Seaver Autism Center for Research and Treatment, Icahn School of Medicine at Mount Sinai, New York, NY, USA. ${ }^{4}$ Graduate School of Biomedical Sciences, Icahn School of Medicine at Mount Sinai, New York, NY, USA. ${ }^{5}$ Department of Psychiatry, Icahn School of Medicine at Mount Sinai, New York, NY, USA. ${ }^{6}$ Department of Natural Sciences, Fordham University, New York, NY, USA. ${ }^{7}$ Morphological Brain Research Unit, Department of Psychiatry, University of Wuerzburg, Wuerzburg, Germany. ${ }^{8}$ Department of Neuroanatomy, Ludwig-Maximilians University of Munich, Munich, Germany.

Received: 13 December 2013 Accepted: 17 February 2014

Published: 24 February 2014

\section{References}

1. Uppal N, Hof PR: Discrete cortical neuropathology in autism spectrum disorders. In The Neuroscience of Autism Spectrum Disorders. Edited by Buxbaum JD, Hof PR. Oxford: Elsevier; 2013:313-325.

2. Kanwisher N, MCDermott J Chun MM: The fusiform face area: a module in human extrastriate cortex specialized for face perception. J Neurosci 1997, 17(11):4302-4311.

3. CDC, Center for Disease Control: Prevalence of autism spectrum disorders autism and developmental disabilities monitoring network, 14 sites, United States, 2008. MMWR Surv Summ 2012, 61:1-19.

4. Piggot J, Kwon H, Mobbs D, Blasey C, Lotspeich L, Menon V, Bookheimer S, Reiss AL: Emotional attribution in high-functioning individuals with autistic spectrum disorder: a functional imaging study. J Am Acad Child Adolesc Psychiatry 2004, 43(4):473-480.

5. Kleinhans NM, Richards T, Sterling L, Stegbauer KC, Mahurin R, Johnson LC, Greenson J, Dawson G, Aylward E: Abnormal functional connectivity in autism spectrum disorders during face processing. Brain 2008 131(4):1000-1012.

6. van Kooten IA, Palmen SJ, von Cappeln P, Steinbusch HW, Korr H, Heinsen

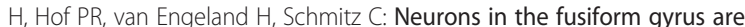
fewer and smaller in autism. Brain 2008, 131(4):987-999.

7. Heinsen $H$, Heinsen $Y L$ : Serial thick, frozen, gallocyanin stained sections of human central nervous system. J Histotechnol 1991, 14:167-173.
8. Heinsen $\mathrm{H}$, Arzberger $\mathrm{T}$, Schmitz C: Celloidin mounting (embedding without infiltration) - a new, simple and reliable method for producing serial sections of high thickness through complete human brains and its application to stereological and immunohistochemical investigations. J Chem Neuroanat 2000, 20(1):49-59.

9. Wegiel J, Kuchna I, Nowicki K, Imaki H, Marchi E, Ma SY, Chauhan A, Chauhan V, Bobrowicz TW, de Leon M, Louis LA, Cohen IL, London E, Brown WT, Wisniewski T: The neuropathology of autism: defects of neurogenesis and neuronal migration, and dysplastic changes. Acta Neuropathol 2010, 119(6):755-770.

10. Caspers J, Zilles K, Eickhoff SB, Schleicher A, Mohlberg H, Amunts K: Cytoarchitectonical analysis and probabilistic mapping of two extrastriate areas of the human posterior fusiform gyrus. Brain Struct Funct 2013, 218(2):511-526

11. Brodmann K: Vergleichende Vergleichende Lokalisationslehre der Grosshirnrinde in Ihren Prinzipien Dargestellt auf Grund des Zellenbaues. Leipzig: Barth; 1909.

12. von Economo C: L'architecture cellulaire normale de l'écorce cérébrale. Paris: Masson; 1927

13. Schmitz C, Hof PR: Design-based stereology in neuroscience. Neuroscience 2005, 130(4):813-831.

14. Sterio DC: The unbiased estimation of number and size of arbitrary particles using the disector. J Microsc 1984, 134:127-136

15. Gundersen HJG: The nucleator. J Microsc 1988, 151:3-21.

16. Cavalieri B: Geometria indivisibilibus continuorum. In Reprinted in 1966 as Geometria Degli Indivisibili. Edited by Bononiae, Typis Clementis Ferronij. Torino: Unione Tipografico-Editrice Torinese:1635.

17. Caspers J, Zilles K, Amunts K, Laird AR, Fox PT, Eickhoff SB: Functional characterization and differential coactivation patterns of two cytoarchitectonic visual areas on the human posterior fusiform gyrus. Hum Brain Mapp 2013. doi: 10.1002/hbm.22364.

doi:10.1186/2040-2392-5-17

Cite this article as: Uppal et al:: Neuropathology of the posteroinferior occipitotemporal gyrus in children with autism. Molecular Autism 2014 5:17.

\section{Submit your next manuscript to BioMed Central and take full advantage of:}

- Convenient online submission

- Thorough peer review

- No space constraints or color figure charges

- Immediate publication on acceptance

- Inclusion in PubMed, CAS, Scopus and Google Scholar

- Research which is freely available for redistribution 